\title{
PHẪU THUẬT NỘI SOI TOÀN BỘ KHÔNG CÓ ROBOT HỖ TRỌ,, TIM ĐẬP VÁ THÔNG LIÊN NHĨ Ở TRẺ NHỎ
}

\author{
Đặng Quang Huy*, Nguyê̂n Công Hưu*, Trần Đắc Đại*, Nguyễn Đỗ Hùng*, \\ Nguyễn Trung Hiếu*, Phạm Thị Minh Huệ*, Đặng Thanh Huờng*, Lê Ngọc Thành*
}

Từ tháng 5/2016 đến tháng 4/2017, 14bệnh nhân (TLN đơn thuần/ TLN kèm TMP lạc chỗ bán phần: $13 / 1$ ) với tuổi trung bình là $7,5 \pm 3,9$ và cân nặng trung bình là $21 \pm 8,8$ kgđược phẫu thuật theo phương pháp NSTB không robot hỗ trợ, tim đập.Cannula động mạch (ĐM) đùi một hoặc hai bên; đặt 3 trocar $5 \mathrm{~mm}$ và 1 trocar $12 \mathrm{~mm}$, chỉ thắt $\mathrm{TMC}$ trên, làm đầy khoang màng phổi bằng $\mathrm{CO} 2$. Miếng vá nhân tạo được sử dụng trong tất cả các trường hợp. Thời gian theo dõi trung bình 5,4 \pm 3,6 tháng (1 tháng đến 11 tháng). Không có biến chứng liên quan phẫu thuật và tử vong sau mổ. Thời gian mổ và thời gian chạy máy trung bình lần lượt là 244,6 $\pm 52,3$ (phút) và 145,9 \pm 40,5 (phút). Bệnh nhân được rút nội khí quản trong vòng 6 giờ đầu, dẫn lưu trong ngày đầu $<60 \mathrm{ml}$. Sau 4 ngày người bệnh không cần dùng thuốc giảm đau và trở về với sinh hoạt bình thường sau mổ 1 tuần. Phẫu thuật NSTBkhông có robot hỗ trợ vá TLN tim đập là phương pháp an toàn và hiệu quả khi thực hiện ở trẻ nhỏ. Người bệnh hồi phục sớm, sẹo mổ có giá trị thẩm mỹ cao đặc biệt ở trẻ gái.

Từ khóa: phẫu thuật tim nội soi toàn bộ, phẫu thuật tim ít xâm lấn, phẫu thuật tim đập, thông liên nhĩ...

\section{I. ĐẠTT VẤN ĐỀ}

Từ những năm 2000, với sự hỗ trợ của hệ thống robot, phẫu thuật nội soi toàn bộ (NSTB) đã lần đầu tiên được ứng dụng trong điều trị bệnh lý tim mạch, trong đó có bệnh thông liên nhĩ (TLN). Nhờ sự linh hoạt của thiết bị và sự chính xác trong từng thao tác, hệ thống robot giúp phẫu thuật viên
(PTV) có thể can thiệp vào những vị trí sâu, không gian chật hẹp với độ an toàn cao. Tuy vậy đến thời điểm này, phẫu thuật nội soi tim ở trẻ em vẫn là thách thức lớn đối với các PTV tim mạch. Mặt khác, chi phí phẫu thuật và chi phí đào tạo rất cao là lý do không nhỏ khiến phẫu thuật NSTB có sự hỗ trợ của robot chưa được ứng dụng rộng rãi. Trong nghiên cứu này, chúng tôi báo cáo kinh nghiệm ban đầu về phẫu thuật NSTB không robot hỗ trợ, tim đập trong điều trị bệnh TLN ở trẻ nhỏ.

\section{II. ĐỐI TƯợNG VÀ PHƯƠNG PHÁP NGHIÊN CỨU}

\subsection{Lựa chọn bệnh nhân}

Từ tháng 5/2016 đến tháng 4/2017, 14bệnh nhân (BN)chẩn đoán TLN (nam/ nữ: 3/11) được điều trị bằng phương pháp phẫu thuật NSTB không có robot hỗ trợ, tim đập. Tiêu chuẩn lựa chọn gồm: (1) TLN lỗ thứ phát đơn thuần, TLN kèm theo TMP lạc chỗ bán phần; $(2)<18$ tuổi với cân nặng $>13 \mathrm{~kg}$. Tất cả BN được siêm âm doppler kiểm tra tình trạng $Đ M$ chậu đùi trước mổ. Những trường hợp kích thước $\mathrm{ĐM}$ đùi quá nhỏ không thiết lập được tuần hoàn ngoại vi bị loại ra khỏi nghiên cứu. BN TLN lỗ tiên phát hoặc TLN kèm bệnh lý khác không được lựa chọn.

\footnotetext{
* Trung tâm tim mạch bệnh viện E

** Bệnh viện Việt Đức

Nguời chịu trách nhiệm khoa học: GS.TS. Lê Ngọc Thành

Ngày nhận bài: 01/08/2017 - Ngày Cho Phép Đăng: 07/08/2017

Phản Biện Khoa học: GS.TS. Bùi Đức Phú

PGS.TS. Đặng Ngọc Hùng
} 


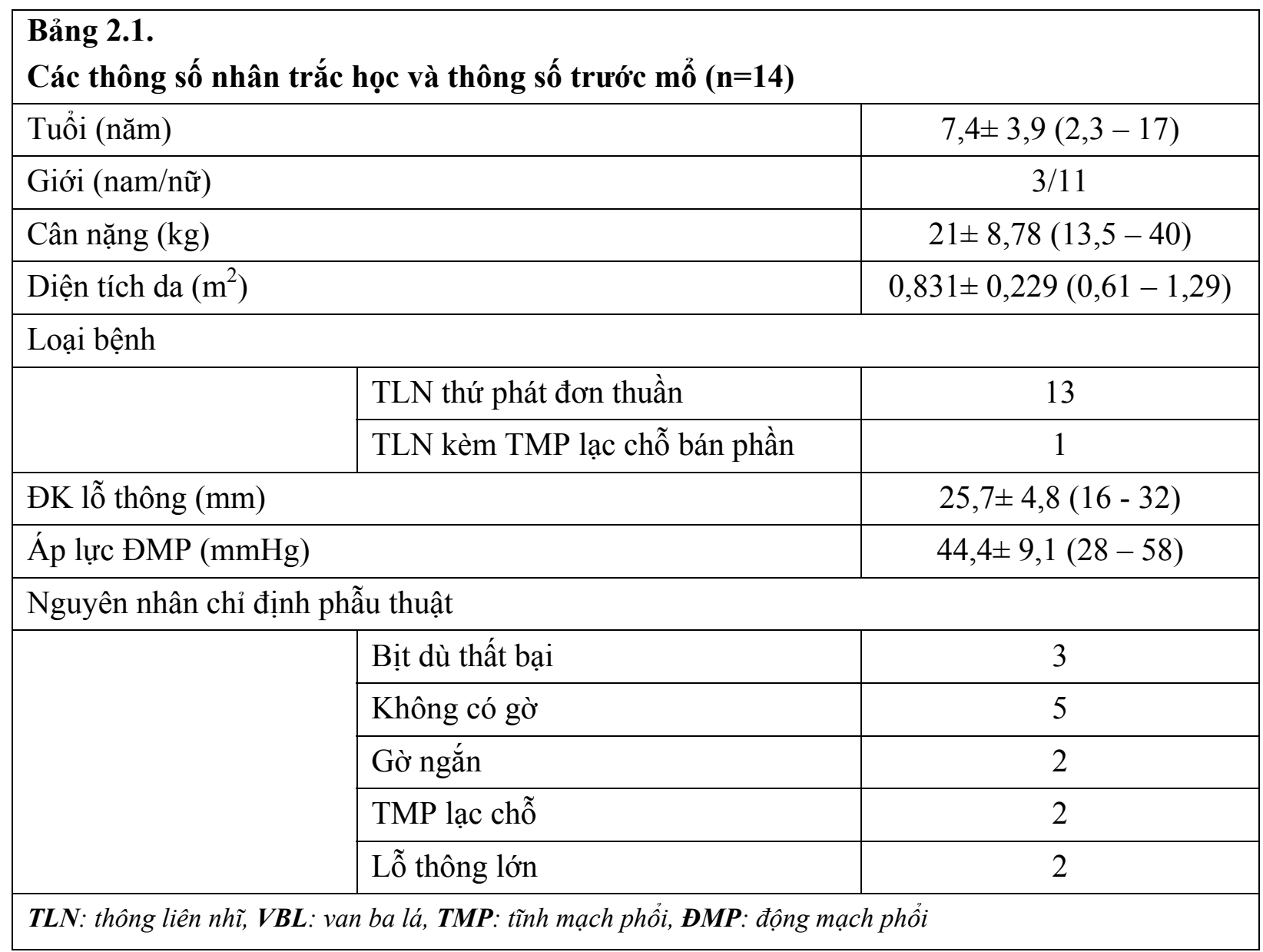

Các thông số nhân trắc học (tuổi, cân nặng, diện tích da, kích thước lỗ thông) trước mổ, các đặc điểm về bệnh học và nguyên nhân chỉ định mổ được trình bày trong Bảng 1 . Phương pháp phẫu thuật được hội đồng khoa học bệnh viện thông qua và được sự đồng thuận của gia đình bệnh nhân.

\subsection{Phương pháp phẫu thuật}

BN được gây mê bằng ống nội khí quản một nòng. Bác sĩ gây mê đặt catheter tĩnh mạch trung ương vào $\mathrm{TM}$ cảnh trong trái. $\mathrm{BN}$ được đặt tư thế nằm nghiêng trái $20-30^{\circ}$, hai tay xuôi theo thân người. Phẫu thuật viên vẽ sẵn vị trí dự định đặt các lỗ trocar.

Để thiết lập tuần hoàn ngoại vi chúng tôi tạo một đường rạch dài $2 \mathrm{~cm}$ ngang ở nếp bẹn bên phải, bộc lộ $\mathrm{ĐM}$ đùi chung và $\mathrm{TM}$ đùi. Ở những $\mathrm{BN}$ có cân nặng $>15 \mathrm{~kg}$, chúng tôi thiết lập đường $\mathrm{ĐM}$ một cách gián tiếp vào $\mathrm{ĐM}$ đùi chung qua một đoạn mạch Dacron số 6 . Cannula $\mathrm{TMC}$ trên và $\mathrm{TMC}$ dưới được đặt qua $\mathrm{TM}$ cảnh trong phải và $\mathrm{TM}$ đùi theo phương pháp Sheldinger. Trước khi đặt trocar, chúng tôi kiểm tra đường $\mathrm{ĐM}$ bằng cách chạy máy thử; nếu với toàn bộ lưu lượng, áp lực đường ĐM $<220 \mathrm{mmHg}$ là chấp nhận được. Nếu áp lực đường ĐM tăng quá $220 \mathrm{mmHg}$, chúng tôi sẽ đặt một đường ĐM phụ ở đùi bên trái với kích thước cannula nhỏ hơn $4 \mathrm{~F}$ so với kích thước dự kiến theo cân nặng $\mathrm{BN}$. Ở những $\mathrm{BN}$ có cân nặng $<15 \mathrm{~kg}$, chúng tôi đặt cannula trực tiếp vào $Đ M$ đùi hai bên, lựa chọn cannula nhỏ hơn 2-4F so với kích thước dự kiến theo cân nặng của $\mathrm{BN}$. 


\begin{tabular}{|c|c|}
\hline \multicolumn{2}{|c|}{$\begin{array}{l}\text { Bảng 2.2. } \\
\text { Các thông số về thiết lập tuần hoàn ngoài cơ thể ngoại vi }\end{array}$} \\
\hline \multicolumn{2}{|l|}{ Cannula ĐM đùi (n=14) } \\
\hline Một bên qua mạch Dacron số 6 & 6 \\
\hline Hai bên chủ động & 3 \\
\hline Một bên thất bại (chuyển thành hai bên) & 5 \\
\hline Kích thước cannula TMC trên $(\mathrm{F})$ & $15,2 \pm 2,1(12-20)$ \\
\hline Kích thước cannula TMC dưới (F) & $16,8 \pm 1,9(14-21)$ \\
\hline
\end{tabular}

Đặt 4 trocar tại các vị trí đã đánh dấu sẵn (hình 2), cụ thể là: 01 trocar $12 \mathrm{~mm}$ tại khoang liên sườn (KLS) $\mathrm{V}$ đường nách trước là tay làm việc chính, 01 trocar $5 \mathrm{~mm}$ tại KLS III đường nách giữa là tay làm việc phụ, 01 trocar $5 \mathrm{~mm}$ tại KLS V đường nách giữa (cho đèn nội soi) và 01 trocar $5 \mathrm{~mm}$ tại KLS VI đường nách giữa (cho đường hút máu về). Sau khi vào đến khoang màng phổi, hệ thống tuần hoàn ngoài cơ thể bắt đầu hoạt động, nhiệt độ thực quản được hạ dần xuống $32^{\circ} \mathrm{C}$, màng tim được mở song song và phía trước so với thần kinh hoành $2 \mathrm{~cm}$.

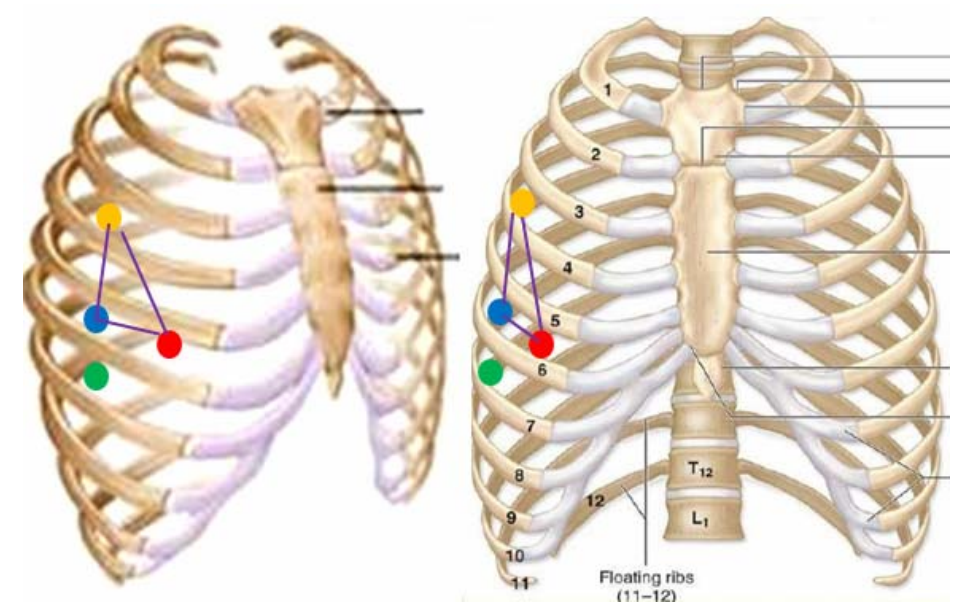

Hình 1 cách thức đặt 4 trocar. Mầu đỏ là vị trí tay làm việc chinh đặt ở KLS V đường nách trước. Mầu vàng là vị trí tay làm việc phu đặt ở KLS III đường nách giữa. Mầu xanh luc là vị trí đặt camera đặt ở KLS V đuờng nách giữa.

Mầu xanh lá cây là vị trí đường hút máu về đặt ở KLS VI đường nách giữa.

Khoang màng phổi và màng tim được làm đầy bởi khí CO2. Mở nhĩ phải (NP) dọc theo rãnh liên nhĩ sau khi đã thắt $\mathrm{TMC}$ trên và $\mathrm{BN}$ ở tư thế Trendelenburg. Tất cả lỗ TLN được đóng bằng miếng vá nhân tạo, khâu vắt. TMP lạc chỗ được tạo đường hầm trong tim dẫn máu về nhĩ trái qua lỗ TLN. Đường mở NP được đóng hai lớp. Tim được làm đầy sau khi thả thắt $\mathrm{TMC}$ trên, tư thế đầu bằng và kiểm tra cầm máu kỹ, màng tim được đóng mũi rời. Ngừng tuần hoàn ngoài cơ thể sau khi đặt 01 dẫn lưu màng tim và 01 dẫn lưu màng phổi. Quy trình còn lại giống như phẫu thuật nội soi đơn thuần. 


\subsection{Chăm sóc sau mổ:}

Bệnh nhân được theo dõi sau mổ tại phòng hồi sức. Chụp Xquang ngực và siêu âm màng tim, màng phổi được thực hiện tại giường để loại trừ biến chứng về phổi (xẹp phổi, tràn dịch màng phổi...). Bệnh nhân được rút ống nội khí quản sớm nhất có thể và được chuyển về bệnh phòng vào ngày hôm sau nếu không cần theo dõi đặc biệt. Giảm đau ngày đầu tiên bằng Morphine, những ngày sau dùng giảm đau bằng non-steroid đường uống. Bệnh nhân và bố mẹ được khuyến khích không dùng thuốc giảm đau ngay khi có thể. Tất cả bệnh nhân sau mổ được kiểm tra bằng siêu âm qua thành ngực và siêu âm doppler mạch máu kiểm tra trước khi ra viện.

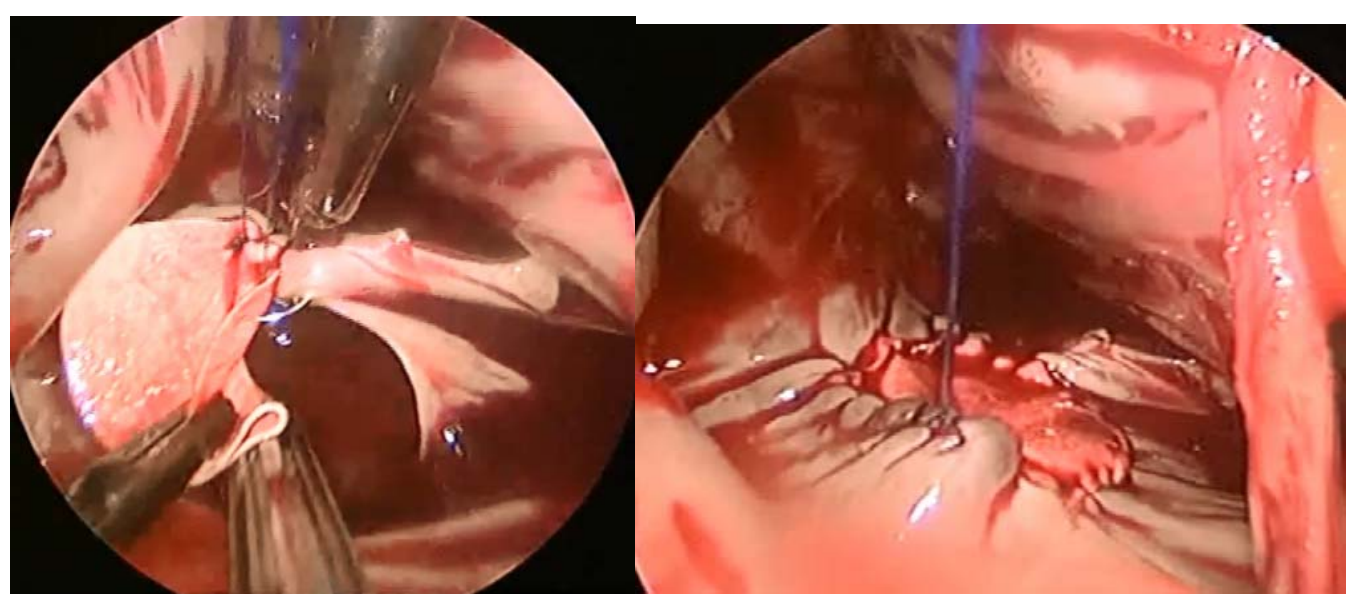

Hình 2, Kỹ thuật vá TLN NSTB. (A) vá lỗ TLN sử dụng miếng vá nhân tạo;

(B) Hoàn thành đưòng khâu vắt vá TLN.

\subsection{Theo dõi sau mổ:}

Bệnh nhân được hẹn khám lại sau mổ 1 tháng, 3 tháng, 6 tháng, 1 năm. Bệnh nhân được khám, đánh giá tình trạng sẹo mổ, sự cân đối giữa hai ngực, tình trạng dị cảm quanh vị trí vết mổ ngực và đùi, sự hài lòng của gia đình và bệnh nhân về vị trí và kích thước sẹo mổ. Bệnh nhân được siêu âm tim qua thành ngực và siêu âm doppler mạch kiểm tra.

\subsection{Phân tích số liệu:}

Số liệu được tính ra trung bình \pm phương sai (S.D.) cho những biến định lượng và tính ra số lượng với tỉ lệ phần trăm cho những biến định tính. Số liệu được quản lý và phân tích bởi phần mềm SPSS 14.0.

\section{KẾT QUẢ}

\subsection{Kết quả sau mổ}

Phẫu thuật được thực hiện thành công ở tất cả các trường hợp. Không có trường hợp nào cần mở rộng vết mổ hoặc chuyển cưa xương ức.Tất cả $\mathrm{BN}$ được thiết lập tuần hoàn ngoài cơ thể ngoại vi. Cannula ĐM được đặt gián tiếp qua một đoạn mạch Dacron ở 11BN;trong đó có $5 \mathrm{BN}$ cần đặt thêm đường $\mathrm{ĐM}$ phụ vào $\mathrm{ĐM}$ đùi trái.Có $3 \mathrm{BN}$ cân nặng $<15 \mathrm{~kg}$, chúng tôi chủ động đặt trực tiếp cannula ĐM đùi hai bên.Ba trường hợp trẻ nhỏ phải sử dụng cannula $\mathrm{ĐM}$ để đặt cho $\mathrm{TMC}$ dưới. Chi tiết về thiết lập tuần hoàn ngoài cơ thể được trình bày trong Bảng 2 . 


\begin{tabular}{|c|c|}
\hline $\begin{array}{l}\text { Bảng } 3 . \\
\text { Các thông số trong và sau mổ }(n=14)\end{array}$ & \\
\hline Thời gian mổ (phút) & $244,6 \pm 52,3(175-350)$ \\
\hline Thời gian chạy máy (phút) & $145,9 \pm 40,5(78-220)$ \\
\hline Thời gian bộc lộ lỗ thông (phút) & $25,4 \pm 4,9(20-35)$ \\
\hline Thời gian vá TLN (phút) & $49,1 \pm 22,1(24-90)$ \\
\hline Thời gian đóng nhĩ phải (phút) & $18 \pm 8,4(10-40)$ \\
\hline Thời gian thở máy (giờ) & $6,4 \pm 4,5(1,25-15)$ \\
\hline Thời gian nằm hồi sức (giờ) & $19,7 \pm 5,3(16-36)$ \\
\hline Dẫn lưu trong 24 giờ đầu (ml) & $55,4 \pm 40,3(0-160)$ \\
\hline Thời điểm không cần dùng thuốc giảm đau sau mổ (ngày) & $3,9 \pm 0,6(3-5)$ \\
\hline Thời gian nằm viện sau mổ (ngày) & $10,1 \pm 2,9(6-17)$ \\
\hline Biến chứng sau mổ (thần kinh, mạch đùi, dị cảm đùi, tồn lưu...) & 0 \\
\hline
\end{tabular}

Thời gian phẫu thuật và thời gian chạy máy trung bìnhlần lượt là $244,6 \pm 52,3$ phút và $145,9 \pm$ 40,5 phút. Tất cả $\mathrm{BN}$ không cần dùng thuốc vận mạch sau ngừng hệ thống tim phổi máy và được rút máy thở trong vòng 6 giờ. Không có $\mathrm{BN}$ nào có biến chứng về thần kinh và biến chứng về mạch máu sau mổ. Sau 3-5 ngày $\mathrm{BN}$ không cần dùng thuốc giảm đau, người bệnh có thể trở lại sinh hoạt bình thường sau mổ 7 ngày (bảng 3 ).Tất cả $\mathrm{BN}$ và gia đình đều rất hài lòng về hiệu quả và tính thẩm mỹ của sẹo mổ.

\subsection{Kết quả theo dõi}

Thời gian theo dõi trung bình là 5,4 \pm 3 ,6tháng, (từ 1 tháng đến 11 tháng). Tất cả lỗ thông được vá kín, không có biến chứng sau mổ liên quan đến hệ thống thần kinh và mạch máu đùi.

\section{BÀN LUẬN}

Theo Van der Linde (2011), TLN là một trong số những bệnh tim bẩm sinh thường gặp nhất với tỉ lệ mắc bệnh ngày càng tăng theo thời gian [1]. Tim mạch can thiệp, với nhiều ưu điểm, đã trở thành lựa chọn hàng đầu trong điều trị TLN tại hầu hết các quốc gia trên thế giới trong hơn 20 năm trở lại đây; tuy vậy ngày càng có nhiều báo cáo về biến chứng lâu dài của phương pháp điều trị ít xâm lấn này [2-4]. Biến dạng lồng ngực và sẹo mổ xấu là những biến chứng không thể tránh khỏi khi phẫu thuật cho những bệnh nhân nhỏ tuổi bằng phương pháp kinh điển - cưa xương ức[5]. Gần đây, việc sử dụng robot trong phẫu thuật tim nội soi đã dần trở nên quen thuộc và cho thấy nhiều ưu điểm khi áp dụng ở những $\mathrm{BN}$ trưởng thành, nhưng có rất ít báo cáo về áp dụng kỹ thuật này ở trẻ nhỏ[ $[6,7]$. Nghiên cứu này công bố kinh nghiệm lâm sàng của chúng tôi trong việc áp dụng phương pháp phẫu thuật NSTB, tim đập, không có sự hỗ trợ của robot ở trẻ nhỏ có cân nặng từ $13.5 \mathrm{~kg}$ trở lên.

Nhiều tác giả thừa nhận phẫu thuật tim đập giúp làm giảm nguy cơ thiếu máu cơ tim và hiện tượng tái tưới máu sau mổ[구 $\underline{8}]$.Tuy vậy, phương pháp này không được sử dụng rộng rãi 
do phẫu trường không sạch máu và tim đập liên tục trong quá trình mổ gây khó khăn về kỹ thuật. Với kinh nghiệm > 120 trường hợp áp dụng phẫu thuật tim đập trong điều trị thông liên nhĩ, chúng tôi nhận thấy đây là phương pháp có nhiều ưu điểm: (1) không can thiệp vào gốc ĐMC giúp rút ngắn thời gian phẫu thuật và giảm nguy cơ chảy máu sau mổ; (2) chúng tôi gặp 2 trường hợp TLN lớn lan tới lỗ xoang vành, trong quá trình vá TLN xuất hiện block dẫn truyền nhĩ thất hoàn toàn, mũi khâu được rút ra và nhịp xoang trở lại sau đó 15-20 phút.

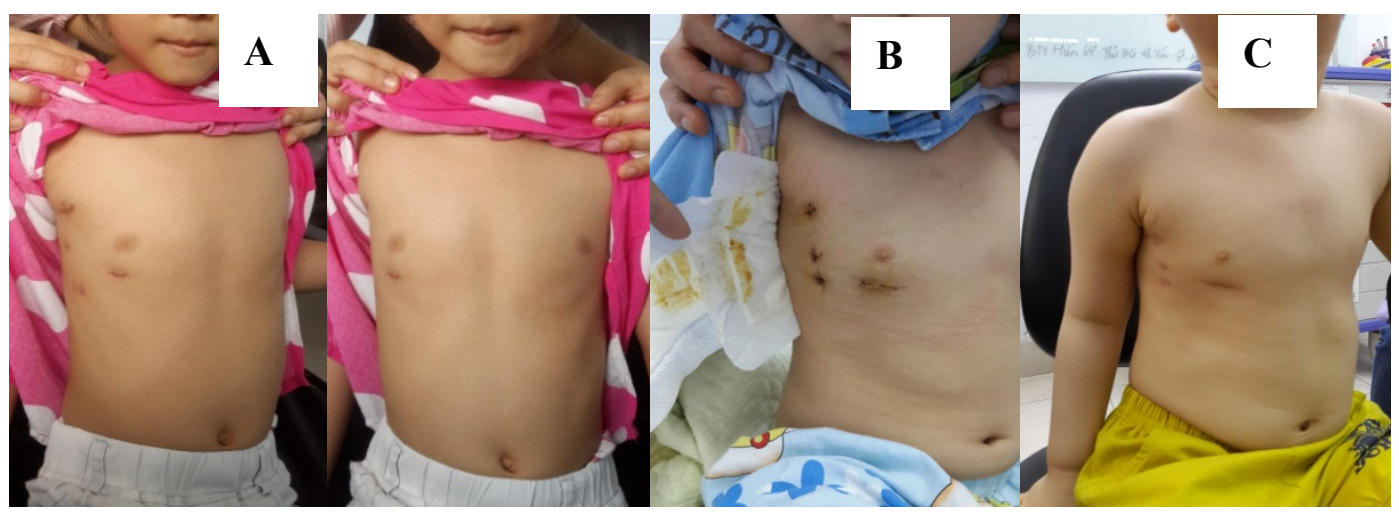

Hình 3. Kết quả sau mổ NSTB không có robot hỗ trợ, tim đập.

(A) BN nũ 7 tuổi sau mổ 1 tháng; (B) BN nũ 4 tuổi ngay sau mổ và (C) BN nam 27 tháng sau mổ 1 tháng

Mặc dù không dùng kim hút gốc ĐMC, chúng tôi không gặp biến chứng về thần kinh do làm đầy liên tục khoang màng tim và màng phổi bằng $\mathrm{CO} 2$, tốc độ bơm $\mathrm{CO} 2$ được bắt đầu bằng $0.5 \mathrm{l} /$ phút và được điều chỉnh dựa trên theo dõi $\mathrm{PaCO} 2$ trong máu liên tục. Krish Chaudhuri đã sử dụng nhiều bài kiểm tra đánh giá chức năng thần kinh của người bệnh được phẫu thuật bằng phương pháp tim đập, làm đầy khoang màng tim bằng $\mathrm{CO} 2$ nhiều tuần trước và sau mổ, kết quả cho thấy không có rối loạn thần kinh nào được ghi nhận liên quan tới phương pháp phẫu thuật này [9] .

Thiết lập tuần hoàn ngoài cơ thể ngoại vi khó khăn và phẫu trường nhỏ hẹp là 2 sự khác biệt chính giữa phẫu thuật tim nội soi ở trẻ nhỏ và người trưởng thành. $\mathrm{DM}$ đùi ở trẻ nhỏ chưa trưởng thành, thường có kích thước nhỏ hơn chuẩn theo cân nặng và hay có phản xạ co thắt dẫn tới áp lực đường ĐM tăng cao ngay sau khi đặt cannula và tăng cao dần sau một thời gian chạy máy. Tăng áp lực đường ĐM là nguyên nhân gây thất bại của phẫu thuật nội soi. Mặt khác, việc cố gắng đặt cannula kích thước lớn vào một $Đ M$ có kích thước hạn chế sẽ dẫn tới tổn thương nội mạc ĐM gây hẹp ĐM đùi và chậu ngoài về sau[10]. Theo Cristian Rosu (2015), ở những $\mathrm{BN}$ trưởng thành có kích thước ĐM nhỏ hơn chuẩn theo cân nặng sẽ có hai giải pháp: (1) cannula gián tiếp qua đoạn mạch Dacron và (2) chuyển từ cannula một bên thành hai bên khi áp lực đường ĐM tăng cao[11]. Do đối tượng nghiên cứu của chúng tôi là trẻ nhỏ, kích thước $\mathrm{ĐM}$ đùi thường nhỏ hơn chuẩn theo cân nặng, do đó tất cả $\mathrm{BN}$ của chúng tôi đều cannula ĐM gián tiếp qua đoạn mạch Dacron số 6 ngoại trừ 3 trường hợp có cân nặng $<15 \mathrm{~kg}$ (ĐM rất nhỏ) chúng tôi đặt cannula trực tiếp hai bên. Nhờ phương pháp này, $6 \mathrm{BN}$ chỉ cần cannula qua đoạn mạch Dacron là đủ ổn định áp lực đường ĐM. Một nỗi lo lớn khi thiết lập 
cannula ĐM đùi ở trẻ nhỏ đó là nguy cơ hẹp ĐM chậu và ĐM đùi chung ngay sau mổ và về lâu dài. Chúng tôi có hai giải pháp cho nguy co này: (1) sử dụng đoạn mạch Dacron và (2) sủ dụng cannula $\mathrm{ĐM}$ có kích thước nhỏ hơn chuẩn theo cân nặng của $\mathrm{BN} 2-4 \mathrm{~F}$. Cho đến thời điểm báo cáo, chúng tôi chưa ghi nhận trường hợp nào có biến chứng về hẹp ĐM chậu, đùi.

Sau 1 năm kinh nghiệm áp dụng phẫu thuật NSTB tim đập điều trị TLN với hơn 40 bệnh nhân (người lớn và trẻ nhỏ), chúng tôi đã rút ngắn được thời gian phẫu thuật và thời gian chạy máy xuống còn $1 / 3$. Giai đoạn hậu phẫu tương tự so với mổ mở, lượng máu dẫn lưu sau mổ trung bình $<60 \mathrm{ml}$ trong 24 giờ đầu tiên, không $\mathrm{BN}$ nào cần truyền máu sau mổ.

Thông thường với nội soi hỗ trợ, người bệnh bị hạn chế vận động tay phải trong nhiều tuần đầu sau mổ do đau và co cơ thành ngực. Với phương pháp mổ NSTB thông qua các lỗ Trocar đường kính từ $5-12 \mathrm{~mm}$ trên thành ngực người bệnh giảm đau sau mổ rất sớm. Chúng tôi chỉ cần cho người bệnh sử dụng Morphine trong ngày đầu tại phòng hồi sức, những ngày sau tại bệnh phòng dùng giảm đau không steroid; trung bình ngày thứ 4 sau mổ người bệnh không cần dùng thuốc giảm đau. BN có thể vận động tay phải bình thường sau mổ 1 tuần.

\section{KẾT LUẬN}

Phẫu thuật NSTB không có robot hỗ trợ, tim đập là phương pháp an toàn và hiệu quả khi thực hiện ở trẻ nhỏ, đồng thời là phương pháp hứa hẹn co thể áp dụng trong điều trị nhiều bệnh lý TBS khác: thông liên thất, thông sàn nhĩ thất bán phần, màng ngăn nhĩ trái...

\section{TÀI LIỆU THAM KHẢO}

1. Van der Linde, D., et al., Birth prevalence of congenital heart disease worldwide: a systematic review and meta-analysis. J Am Coll Cardiol, 2011. 58 (21) p. 2241-7.
2. Jalal, Z., et al., Long-term Complications After Transcatheter Atrial Septal Defect Closure: A Review of the Medical Literature. Can J Cardiol, 2016.

3. Amin, Z., et al., Erosion of Amplatzer septal occluder device after closure of secundum atrial septal defects: review of registry of complications and recommendations to minimize future risk. Catheter Cardiovasc Interv, 2004. 63(4): p. 496-502.

4. Krumsdorf, U., et al., Incidence and clinical course of thrombus formation on atrial septal defect and patient foramen ovale closure devices in 1,000 consecutive patients. J Am Coll Cardiol, 2004. 43(2): p. 302-9.

5. Plass, A., et al., Titanium plate osteosynthesis for the correction of severe sternal deformity in a 13-year-old boy. Interact Cardiovasc Thorac Surg, 2008. 7(5): p. 935-7.

6. Wang, F., et al., Totally thoracoscopic surgical closure of atrial septal defect in small children. Ann Thorac Surg, 2011. 92(1): p. 200-3.

7. Ma, Z.S., et al., Totally thoracoscopic closure for atrial septal defect on perfused beating hearts. Eur J Cardiothorac Surg, 2012. 41(6): p. 1316-9.

8. Mo, A., et al., Efficacy and safety of onpump beating heart surgery. Ann Thorac Surg, 2008. 86(6): p. 1914-8.

9. Chaudhuri, K., et al., Carbon dioxide insufflation in open-chamber cardiac surgery: a double-blind, randomized clinical trial of neurocognitive effects. J Thorac Cardiovasc Surg, 2012. 144(3): p. 646-653 e1.

10.Sagbas, E., et al., Mid-term results of peripheric cannulation after port-access surgery. Interact Cardiovasc Thorac Surg, 2007. 6(6): p. 744-7.

11. Rosu, C., et al., Preoperative vascular imaging for predicting intraoperative modification of peripheral arterial cannulation during minimally invasive mitral valve surgery. Innovations (Phila), 2015. 10(1): p. 39-43. 